\title{
Sustainable waste management in hospitals
}

\author{
H. Daxbeck ${ }^{1} \&$ P. Amrusch ${ }^{2}$ \\ ${ }^{1}$ Resource Management Agency, Vienna, Austria \\ ${ }^{2}$ University of Vienna, Austria
}

\begin{abstract}
This paper refers to the waste management optimisation in hospitals. The goal is to develop the base for selection and implementation of waste prevention measures in hospitals, as well as to take practical action towards the preparation of waste prevention concepts.

The application of the input-output analysis enables the identification and quantification of weak spots and waste prevention potentials in hospitals. The input-output analysis is built by considering the consumption (pieces) from the cost control and linking it with the analysis of the most relevant articles in a database: weight, composition and change during consumption and the correct waste disposal fractions are determined. In this way, the path of an article through the hospital can be described, from the purchase to the discharge as waste, and potential weak spots can be identified.

Results show which articles are relevant for the contents of individual waste fractions. Waste gets thus a face, i.e. the contribution of each article to the total amount is known and steering measures can be derived and implemented. In this way, the basis is created for an efficient waste or environmental management.

The benefits for hospitals include the fact that material flow analysis enables the identification and quantification of weak spots and waste prevention potentials in hospitals. Moreover, the outcome of input-output analysis is a basis for success in terms of efficiency improvements and monetary savings. As long as the database is being continuously updated, annual changes become detectable, and success resulting from implemented measures can be quantified. Identification of specific environmental projects is possible: The projects were developed together with the personnel. The innovation of this project is defined by the direct linking and balancing of purchase data with disposal data in the hospitals.
\end{abstract}

Keywords: waste, waste management, environmental management, waste prevention, material flow analysis, input-output analysis, material accounting, hospital, hospital waste, health care. 


\section{Introduction}

Input-output analyses are considered to be an important prerequisite for the implementation of concepts of waste prevention and environmental management. Generally input-output analyses are purely expressed in monetary terms, focusing on the comparison of new waste policies. For an important contribution analyzing extended relationships into more detail by means of input-output analyses, see, e.g., Nakamura and Kondo [6]. This paper aims at contributing to the methodological improvement of the input-output analyses in waste management in hospitals.

Waste prevention primarily occurs at source. In order to take effective waste prevention measures, awareness about waste composition is needed. Hence, indifferent projects, the basis as well as methods for waste analysis at source are developed and enhanced and in the intervening time adopted by several hospitals. Environmental management in hospitals aims at reducing waste, qualitatively and quantitatively, not only for environmental reasons, but also due to the relevance of cost reduction.

From the cost accounting perspective relevant measures of cost reduction on the purchase-side are well established, whereas waste management decision making is generally more intuitive than systematic. The output-based waste assessment and analyses does not suffice for the input-based monitoring of waste flows. Relevant solutions to qualitative problems regarding, i.e. the PVC flow in hospitals, are often not on hand due to the difficulty of unavailability of data and the lack of systematic data processing.

\section{Goals}

The main aim of the paper is to represent the basis for an efficient waste and environmental management as well as resource-based management of hospitals. These results will serve as an essential requirement for further concepts of waste management as well as measures to be taken with respect to further projects in hospitals waste management.

\section{Methodology}

\subsection{Cost accounting as a starting point}

On the input side, the amount of purchased articles is recorded in detail within the cost accounting. The individual consumption of each article within each cost accounting interface is documented. Logically, the mass input flow can be easily traced by applying the data from the cost accounting. However, the records of the amounts consumed consider article-specific categories, such as pieces, packs, rolls, canisters, and similar. The conversion of these categories into mass flows presupposes knowledge of the articles' weights.

The data base for the determination of the articles' weights is given by the annual consumption data. In a hospital of about 1,000 beds, approximately 
10,000 different articles are annually consumed. The weight determination for all employed articles is thus possible only at a great expense.

The Pareto Rule well-known from the stock management says that the vast majority of a mass flow is caused by only a fraction of the articles consumed. Based on this, the instrument of the ABC-analysis has been developed that allows for the identification of exactly those few articles. By means of the ABCanalysis, for the weight determination only those articles can be selected that account for at least $80 \%$ of the total consumption.

These few articles are analysed in terms of their weight, the weight of their packaging and of their overpack. Further, any change of the article during its use is traced. Afterwards, the article and its packaging are allocated to the corresponding waste and potential recyclables fractions, in accordance to the waste management concept of the investigated hospital. This way, an ArticleWaste-Register is developed for the analysed articles [1].

Packaging materials are generally paid extraordinary attention within the waste management. The real relevance of this fraction for the waste disposal of a hospital can be identified if not only the article itself is considered during the weight analysis but also the weight of the packaging and all overpacks that accompany the article from its delivery up to its use. This way, an overview is gained over the input into a hospital, a general assessment of the waste management is enabled, and a base is created for a waste and environmental management, respectively.

\subsection{Elaboration of the Article-Waste-Register}

The Article-Waste-Register serves to decompose the article and the packaging material in order to distribute to the available waste and recycling fractions. Thereby, variations in weight, caused by the article use, have to be considered (such as medicine taken by patients, blood samples taken). Details about weight and the composition of articles along with their packaging material can be obtained by suppliers and producers or are determined by own analysis. The analysis of changes in weight based on the utilization and determination of disposal paths requires exact information about article use and the waste management system of the hospital. The systematic registration of weights and the allocation to the relevant output flows creates a data base linking output and input flows.

This Article-Waste-Register clearly attributes to each article along with its packaging material the relevant disposal paths based on the waste management concept of the hospital. In the investigated hospitals, an Article-Waste-Register was implemented for the most important articles, whereby the optimal disposal paths of the articles and their packaging material were registered into the data base.

These data are summarized into the MS-SQL-based software tool „Der Connector", by which data can be processed. In this way, data on waste and purchase-related data are interconnected providing a starting point for a variety of optimization possibilities. Thereby, the Article-Waste-Register constitutes a basis for most important articles in terms of masses. The continuous adding up of 
new articles constantly increases the registration degree of masses. Furthermore, the article analyses and description is amplified. In this way, the understanding of material flows, such as PVC or relevant hazardous substances (such as quicksilver) is possible due to the supplementation of the relevant material concentrations.

\subsection{The transfer into the material and/or substance flow analysis}

The establishment of the link between the Article-Waste-Register with the input data deduced form cost accounting enables the assessment of the input and the theoretical output in terms of mass flows to be compared with the actual disposal flows. Thereby an input-output-analysis of flows of the hospital is created.

Since the Article-Waste-Register is based on the strict compliance with the individual waste management concept of the relevant hospital, only mass flows are calculated which pile up within the general framework of the hospital. Thereby, fixed goals are determined to correctly evaluate and compare the current state of the waste management system with the measures to be taken.

Due to the straight link to the cost accounting mass- and material evaluations are possible, which were only usual in monetary and quantitative terms up to now.

For instance, in this way, the contribution of individual articles or groups of materials to the total waste volume can be identified and assessed. Due to the consolidation of more cost centres, evidence is given not only on the level of wards but also on the level of any arbitrary organizational unit of the hospital.

In addition to the quantitative representation in the form of mass flow balances, a quantitative account by means of material flow balances (e.g., of PVC) is possible.

\section{Results}

The possibilities of interpreting and demonstrating input-output analyses are varied [2].

The input-output-analysis of the hospital "KHL" (1,000 beds) shows an annual article consumption of 2.4 Million $\mathrm{kg}$, whereby energy sources and water consumption is not considered. In the hospital "KHL" about 10,000 different articles are purchased annually, coming up to 28 Million units. The results of the input-output-analysis show that around $20 \%$ of the articles $(1,850)$ result in $80 \%$ of the input flows of the hospital. Considering the total water consumption, the hospital "KHL" employs about 146 Million kg of non-durable articles.

After a short time almost about $60 \%$ of these articles finish in the solid waste. In total the hospital "KHL" collects 33 waste and waste materials. The sum of these fractions results in almost the half (49\%) of the non-hazardous waste. On average $46 \%$ of these waste materials are lead to the recycling process through different waste fractions (e.g., paper, glass, swill), whereas the hazardous waste amounts to around $5 \%$. 


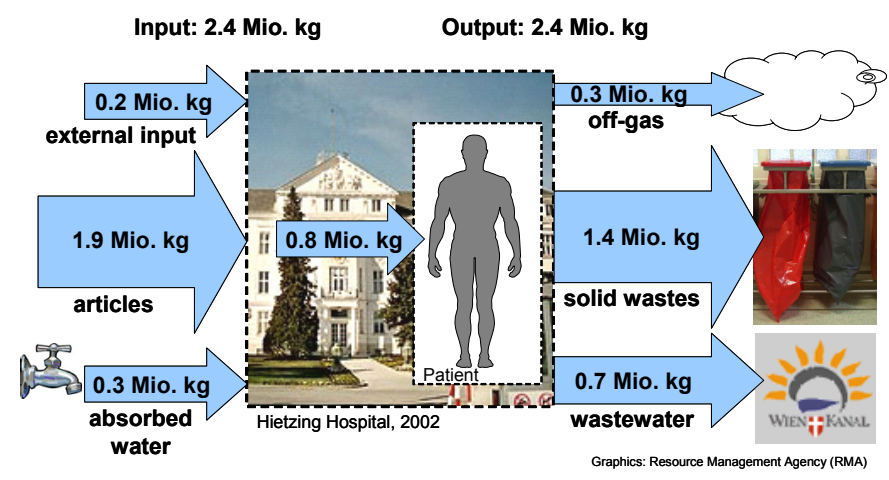

Figure 1: Input-Output analysis of the Hietzing Hospital [2].

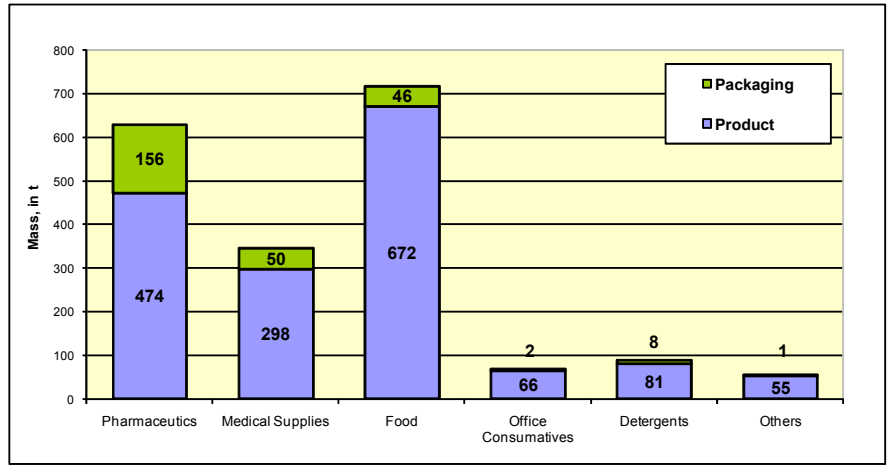

Figure 2: Input-Output analysis of the KHL Hospital.

About $1 / 3$ of the input are consumed by patients to be sort out mainly into the waste water. This division is clearly reflected in the comparison of different product groups. Figure 2 shows how the attribution of articles to the relevant product groups accomplished. The main mass flow in the hospital is characterized by food (51\%), whereas the percentage of medical articles is with $45 \%$ slightly smaller. The contribution of office supplies and packaging material is minor; usually the amount of packaging materials is between 10 und $15 \%$. Consequently, the packaging material is not primarily found in the waste material fractions, but articles themself constitute the main share of waste. In this way, the relevant sensitive sections are identified to be significantly influenced by specific measures in order to reduce the amount of waste.

For all the investigated waste fractions a target-performance-comparison can be done by means of the data base. Thereby, theoretically calculated values (target-performance-values) are confronted with the actual waste quantities (see Figure 3). As a consequence, weak points and possible economic measures (saving potentials) are indicated. Figure 3 displays the target-performancecomparison of non-hazardous waste, exemplified by 3 hospitals. 
In the hospital "PRE" no deviation is observed with respect to non-hazardous waste, i.e., the actual quantity exactly corresponds to the quantity arising according to the correct putting into practice of the concept of waste management. In the hospital "PRE" a very successful environmental management system was introduced 10 years ago. In contrast, in the other two hospitals deviations are considerable. The quantity of the waste disposed is substantial, showing that the implementation of the concept of waste management is improper and contains to many mistakes. In terms of $\mathrm{kg}$ per year, the optimization potential of the non-hazardous waste in the hospital "KHL" amounts to $500,000 \mathrm{~kg}$.

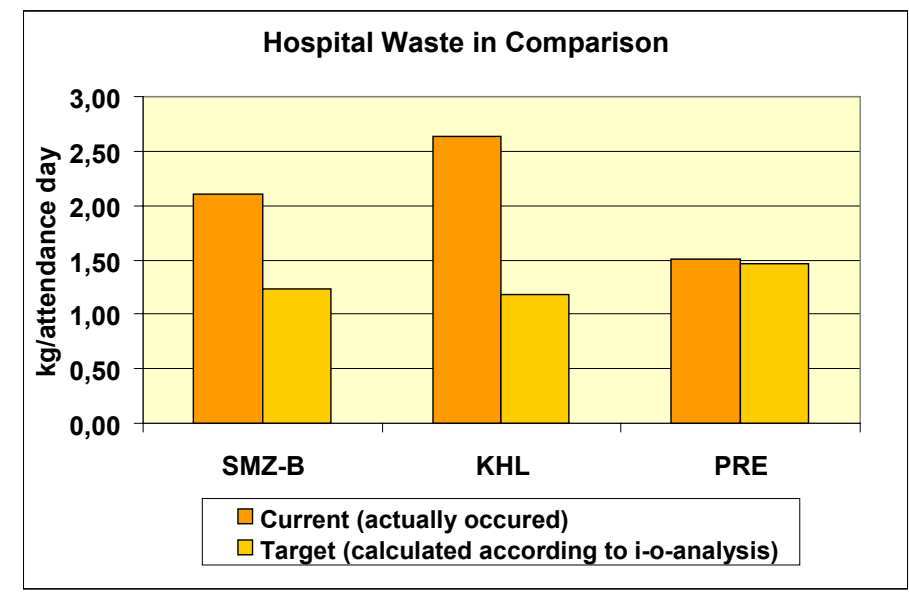

Figure 3: Target-Performance-Comparison of non-hazardous waste for three hospitals. The deviation of target and performance values indicates optimization potentials [2].

The rough analysis of waste flows supports the identification of individual waste or waste material flows. However, this information is not sufficient for taking the relevant action or developing concepts of waste management. Hence, a detailed inspection of the specific waste fractions is required. By analyzing the outcome from the Article-Waste-Register, it is possible to identify the contents of the waste fractions, as the example of non-hazardous waste of the hospital "KHL" shows.

Detailed information on contents of waste fractions serves as a basis for further waste management measures or projects.

In this way, data can be drawn, e.g., for the development of projects in the context of the sensible handling with medical articles, in order to reduce consumption on the input-side and to make a contribution to waste prevention. The utilization of the softeners DEHP (Diethylhexylphthalat) for PVCcontaining medical articles can have negative health impacts on patients, whereas patients have to be protected from the contact with PVC. PVC-balances are considered to be a useful basis for prioritization. For instance, the PVC- 
balance of the hospital "PRE" demonstrates, which articles are mainly responsible for the PVC-flow in the hospital. Input-output analyses have been realized by this hospital since 2000. Hence, the variations in PVC-flows are measurable for recent years. On the basis of the PVC-balance sheet, the flow of PVC could be reduced by more than $60 \%$ in the hospital "PRE".

Table 1: Demonstrates the composition and weights of non-hazardous waste components of the hospital "KHL" (excerpt).

\begin{tabular}{|l|r|r|c|}
\hline \multicolumn{1}{|c|}{ Article description } & $\begin{array}{c}\text { Weight } \\
{[\mathrm{kg}]}\end{array}$ & $\begin{array}{c}\% \text { of the } \\
\text { fraction }\end{array}$ & $\begin{array}{c}\text { Cum. } \% \\
\text { of the } \\
\text { fraction }\end{array}$ \\
\hline Plegable towel 250x310mmC-Falzung 1-lg & 55.932 & $14 \%$ & $14 \%$ \\
\hline Waste sack orange 700x1200mm & 26.760 & $7 \%$ & $20 \%$ \\
\hline Glove - U-H Latex unsteril ungep.M & 21.180 & $5 \%$ & $26 \%$ \\
\hline Glove - U-H Latex unsteril ungep.L & 15.570 & $4 \%$ & $30 \%$ \\
\hline Infusion pres. 150cm & 13.845 & $3 \%$ & $33 \%$ \\
\hline Scrubbing-glove 1x (LB:A) beschichtet & 12.730 & $3 \%$ & $36 \%$ \\
\hline Patient sheet 60x60cm & 12.283 & $3 \%$ & $39 \%$ \\
\hline Cleaning rag 1x normal 30x40cm & 12.137 & $3 \%$ & $42 \%$ \\
\hline Glove - U-H Latex unsteril ungep.S & 11.122 & $3 \%$ & $45 \%$ \\
\hline Disposable nappy adults 1200ml XL & 9.602 & $2 \%$ & $47 \%$ \\
\hline Incontinence padding 0900ml Standard & 8.734 & $2 \%$ & $49 \%$ \\
\hline BIO Full-cream milk & 8.602 & $2 \%$ & $52 \%$ \\
\hline
\end{tabular}

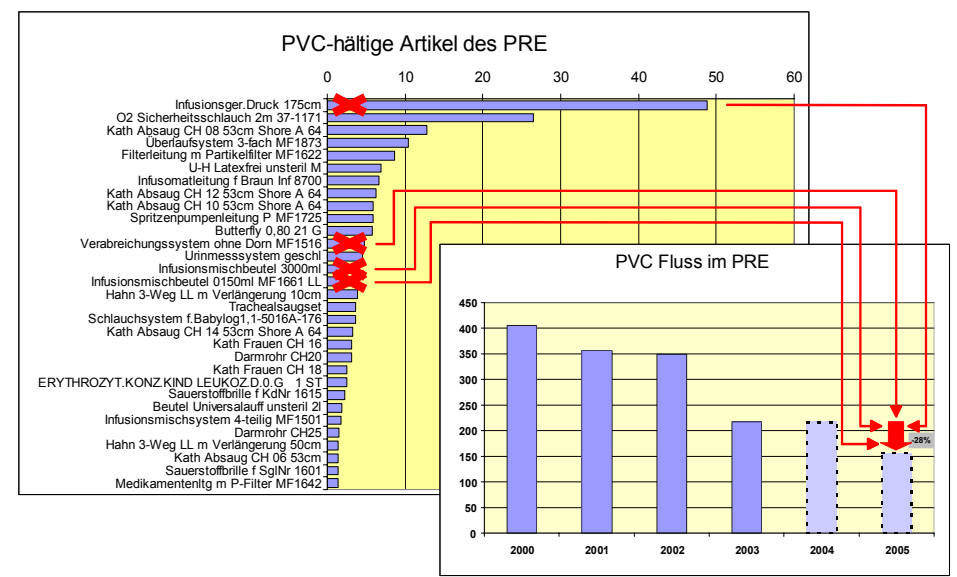

Figure 4: List of PVC-containing medical articles with respect to the quantitative contribution of masses and representation of the reduction of the PVC-mass-flows by $1 / 3$ due to substitution of the 5 marked PVC-containing articles in the hospital "PRE" (indications are given in terms of $\mathrm{kg} / \mathrm{a}$ ) [4]. 
On the basis of input-output analyses, the hospital "KHL" was able to undertake further more than 10 project ideas with different priorities $[2,3]$.

In summary, it can be concluded that waste management projects conducted in the hospital "KHL" within the last years lead to substantial improvements in the context of waste and environmental management preparing new grounds for sustainability and environmental protection.

At the beginning we emphasize environmental work in waste management and organizational improvements, such as waste separation improvements and training. Actions set on the output-side, in contrast, focus on non-hazardous hospital waste as well as waste materials (e.g., paper, glass, plastic and metal). Recently, further optimization potentials in terms of waste management had to be identified in the wards. At present, optimization measures of the article employment concentrate on the reduction of quantities of waste, consciousness raising as well as on resource protection, whereby six priorities were identified (such as gloves, paper towels or photocopying paper) [5]. The actions taken in recent years contributed to annual cost reductions of $€ 79,000$.- or $13 \%$ of the hospital disposal costs, respectively.

\section{Conclusions}

Input-output analyses, linking purchase and discharge are held to be the basis for consciously managing flows in enterprises. The quantitative and qualitative association between articles used and the occurring waste can be set up on the basis of input-output-analysis relating purchase to disposal, which is considered to be a basis for intentionally monitoring the flows in enterprises. The better flows are known, the more efficient can outcomes from the actions be controlled, assessed and predicted. The data collected (Article-Waste-Register) and the data base implemented (Der Connector) represent an efficient optimization tool in waste management. The Article-Waste-Register contains information on the composition and disposal of the relevant article. The identification of articles on the output-side allows for an efficient management of input-side acquisition activities.

It was shown that it is possible to analyze material flows with a justifiable effort supported by an enterprise in the service sector. In this way, prerequisites for the accounting balance of goods and materials are created.

In the investigated hospitals the methodological basis for the initiation of concrete projects of waste prevention could be created and put in practice, accordingly. The success was not only based on waste reduction, but also quality of environmental management could be enhanced. The benefits go beyond waste management issues, as also health-related advantages are pointed out, as the example on the PVC-balance as a basis for health-preventive problems points out. However, efficient waste management requires interdisciplinary collaboration, whereby interdisciplinary teams are a necessary requirement for the success of the implementation and development of concepts of waste management. 


\section{References}

[1] Daxbeck, H.; Neumayer, S.; Brunner, P. (1999) Entwicklung von Grundlagen zur Institutionalisierung von Stoffstromanalysen in Krankenhäusern. Projekt AKIN-B. Endbericht. Technische Universität Wien. Institut für Wassergüte und Abfallwirtschaft. Abteilung Abfallwirtschaft. Wien.

[2] Daxbeck, H.; Neumayer, S.; Kampel, E. (2004) Nachhaltige Abfallvermeidung in Wr. Krankenanstalten und Pflegeheimen. Erarbeitung von Methoden, Grundlagen und Initiierung von konkreten Umsetzungsmaßnahmen. Projekt NABKA. Endbericht. Projekt im Rahmen der INITIATIVE "Abfallvermeidung in Wien". Ressourcen Management Agentur (RMA). Initiative zur Förderung einer umweltverträglichen nachhaltigen Ressourcenbewirtschaftung. Wien.

[3] Daxbeck, H.; Berzsenyi, J.; Stanic, L.; Neumayer, S. (2005a) Aktualisierung der Abfalldatenbank im Krankenhaus Lainz und im Preyer'schen Kinderspital für das Jahr 2003. Projekt AKTAB. Endbericht. Projekt im Rahmen der INITIATIVE Abfallvermeidung in Wien. Ressourcen Management Agentur (RMA). Initiative zur Förderung einer umweltverträglichen nachhaltigen Ressourcenbewirtschaftung. Wien.

[4] Daxbeck, H.; Brandt, B.; Berzsenyi, J.; Stanic, L.; Neumayer, S. (2005b) Identifikation der PVC-hältigen medizinischen Artikel und Erstellung einer PVC-Bilanz. Projekt VEMED - BILANZ. Projekt im Rahmen der INITIATIVE "Abfallvermeidung in Wien". Ressourcen Management Agentur (RMA). Initiative zur Förderung einer umweltverträglichen nachhaltigen Ressourcenbewirtschaftung. Wien.

[5] Daxbeck, H.; Brandt, B.; Stanic, L.; Neumayer, S. (2006) Analyse der Möglichkeiten einer Optimierung des Artikeleinsatzes und der Altstoffsammlung zur Reduktion der Abfallmengen und Initiierung deren Umsetzung. Projekt AMOR. Ressourcen Management Agentur (RMA). Initiative zur Erforschung einer umweltverträglichen nachhaltigen Ressourcenbewirtschaftung. Wien.

[6] Nakamura, S; Kondo, Y. (2002) Input-Output Analysis of Waste Management, Journal of Industrial Ecology, Vol 6 (1) 39-63. 